\title{
Synthesis of Mica
}

\author{
Alvin Van Valkenburg and Robert G. Pike
}

\begin{abstract}
A synthetic fluorophlogopite mica $\left(\mathrm{KMg}_{3} \mathrm{AlSi}_{3} \mathrm{O}_{10} \mathrm{~F}_{2}\right)$, in which the $(\mathrm{OH})$ ions that are normally found in normal micas were completely replaced by fluorine, has been synthesized. This material has essentially the same physical and electrical properties as natural phlogopite mica, except with somewhat lower flexibility. To grow large, usable sheets of mica, it is necessary to obtain preferred crystal orientation, which depends primarily on controlled thermal gradients, batch composition, and rate of cooling. Platinum crucibles were found to be the best material for holding the batch during the melt. Data on the physical, electrical, thermal, and chemical properties of the synthetic mica are given.
\end{abstract}

\section{Introduction}

"Mica" is a general term used to describe a series of silicate minerals that are characterized physically by a perfect basal cleavage and yield with ease thin, tough laminas. Commercially, the two most widely used micas in the electrical industry are the muscovite and phlogopite types. These are important because of their high dielectric strength, thin laminas, high resistance to heat, flexibility, and low unit cost. No substitute has yet been found for these minerals. Because of the strategic importance of the better grades of mica and the failure of domestic supplies to meet our needs, the possibility of the development of a synthetic mica to replace natural mica in wartime has been of great interest.

Claims for the synthesis of mica date back to about 1880. A summary of the work of early investigators is given in F. W. Clarke's "Data of geochemistry", U. S. Geological Survey Bulletin 770,1924 . J. H. L. Vogt [1] ${ }^{1}$ analyzed slags from copper smelting in Sweden and reported a magnesium mica, which may have been a phlogopite. Fouqué and Lévey [2] synthesized a mica trachyte by heating a powdered granitic glass with water under pressure; scales of mica were reported. C. Doelter [3], P. Hautefeville [4], L. P. de Saint-Gilles, and $\mathrm{K}$. Chrustschoft [5] used fluorine compounds in fusing various silicates, both natural and artificial, and obtained micas. Later, D. P. Grigor'er [6] in his systematic studies on the synthesis of micas demonstrated the importance of fluorine in the structure of micas.

A synthetic fluorine phlogopite mica is not a unique product, as many natural phlogopite micas contain fluorine as a partial replacement for hydroxyl. This substitution can be readily accomplished because the ionic radius of fluorine, $1.33 \mathrm{~A}$, is approximately the same as that of the $(\mathrm{OH})$ ion, 1.40 A. Their respective volumes are fluorine 9.86 and $(\mathrm{OH}) 11.48 \mathrm{~A}^{3} \cdot \mathrm{F}^{-1}$ and $(\mathrm{OH})^{-1}$ each have $2 \mathrm{~K}$ and $8 \mathrm{~L}$ electrons, but $\mathrm{F}^{-1}$ has one nucleus with a charge of +9 , and $(\mathrm{OH})^{-1}$ possesses two nuclear charges, +8 and +1 , respectively. The unique feature of the synthetic fluorine phlogopite is that fluorine ions completely replace the hydroxyl ions.

\footnotetext{
1 Figures in brackets indicate the literature references at the end of this paper.
}

One of the first patents on a process for producing synthetic mica by fluorination was issued in 1919 to the German industrial company of Siemens \& Halske, German patent DRP No. 367,537. Subsequent patents were issued to both German and American companies, but no attempts were made to commercialize them. At the conclusion of World War II the successful synthesis of a fluorine mica in Germany in laboratory melts as large as $100 \mathrm{~kg}$ was reported. Active work on mica synthesis had begun in 1938 by the Siemens-Schuchert concern in Berlin and was continued under the leadership of $\mathrm{V}$. Middel until late 1944. In 1941, laboratory research on the properties and crystallization of synthetic mica was also started at the Kaiser-Wilhelm Institute fur Silikatforschung and continued through most of the war. The German work demonstrated that a synthetic fluorine phlogopite mica with a composition of $\mathrm{K}_{4} \mathrm{Mg}_{12} \mathrm{Al}_{4} \mathrm{Si}_{12} \mathrm{O}_{40} \mathrm{~F}_{8}$ could be readily crystallized from a melt. Although the Germans were successful in crystallizing a fluorine mica, apparently development never reached the state of fabrication of the mica into shapes for commercial articles.

Data on the electrical properties of synthetic mica obtained at the conclusion of World War II indicated only that synthetic fluorine phlogopite had electric constants equal to or better than that of natural phlogopite.

When it became known that it was possible to synthesize a fluorine phlogopite mica, the Department of the Navy, through the Bureau of Ships and the Office of Naval Research, and the Department of the Army, through the Signal Corps, planned a joint synthetic-mica program. Research contracts were negotiated with the U. S. Bureau of Mines at Norris, Tenn., the Colorado School of Mines at Golden, Colo., and the National Bureau of Standards at Washington, D. C. These three groups have been working on the various problems involved in the synthesis of mica, exchanging ideas, and at joint meetings discussing technical data.

The synthetic-mica research program at the National Bureau of Standards is part of a broad program of fundamental research on fluorine-type artificial minerals. The general purpose of the mica program is to determine the laws governing the growth of this mineral and to compare the physical, 
electrical, and chemical properties of the synthetic mica with those of its natural analogue. Exploratory experiments were initiated in November 1946 and continued with Bureau appropriations, as personnel and funds allowed, until early in 1947, when funds of the Office of Technical Services, Department of Commerce, permitted greater activity on the project. On June 30,1947, funds from this source were discontinued. Thereafter, this work was supported by the Office of Naval Research.

\section{Experimental Work}

As a starting point in the mica-synthesis program, the first experiments were patterned after the German work as reported in the Fiat publications. A mica batch, with a composition corresponding to the German formula published in the Office of Military Government Fiat Report 746, was prepared The batch was adjusted to give a final composition of:

\begin{tabular}{|c|c|}
\hline & $\begin{array}{l}\text { Percentage } \\
\text { by weight }\end{array}$ \\
\hline $\begin{array}{l}\mathrm{Al}_{2} \mathrm{O}_{3} \\
\mathrm{MgO} \\
\mathrm{SiO}_{2} \\
\mathrm{~K}_{2} \mathrm{SiF}_{6}\end{array}$ & $\begin{array}{l}\text { 11. } 6 \\
32.6 \\
30.7 \\
25.1\end{array}$ \\
\hline
\end{tabular}

A 1-g sample of batch material was placed in a sealed platinum-foil envelope and heated to 1,450 ${ }^{\circ} \mathrm{C}$ for 10 minutes. The charge was then cooled at a controlled rate of $3 \mathrm{deg} / \mathrm{min}$ to $1,300^{\circ} \mathrm{C}$, after which the furnace was cooled rapidly to room temperature. The sample had completely crystallized, forming small interlocking mica crystals up to $3 \mathrm{~mm}$ in diameter. Individual crystals cleaved readily into thin flexible flakes. Impurities in the form of irregular white patches or cloudy surfaces occurred in thin layers parallel to the cleavage directions. This preliminary experiment demonstrated that synthetic fluophlogopite mica, with a composition similar to the natural phlogopite mica, could be readily crystallized from a melt. Additional experiments indicated that the major problems involved in growing mica were: composition of batch; control of losses by volatilization to prevent melts from changing composition; composition of crucible; attainment of uniform and controlled thermal gradients within melts to give a preferred orientation to growing crystals; prevention of excessive seed crystal formation at the beginning of crystallization.

\subsection{Composition and Melting Point}

Phase determinations were made on a batch consisting of:

\begin{tabular}{|l|c|}
\hline & $\begin{array}{c}\text { Percentage } \\
\text { by weight }\end{array}$ \\
\hline $\mathrm{Al}_{2} \mathrm{O}_{3}$ & 11.79 \\
$\mathrm{MgO}_{2}$ & 27.99 \\
$\mathrm{SiO}_{2}$ & 34.74 \\
$\mathrm{~K}_{2} \mathrm{SiF}_{6} \ldots \ldots$ & \\
\hline
\end{tabular}

This composition, which approximates the ideal phlogopite formula $\mathrm{KMg}_{3} \mathrm{AlSi}_{3} \mathrm{O}_{10} \mathrm{~F}_{2}$ with the exception of an excess of $\mathrm{F}_{2}$, yielded the best crystals. In preparing the batch materials prior to the melting operation, care must be taken to eliminate water vapor and $\mathrm{CO}_{2}$ from the raw ingredients, as the presence of these in the batch may cause premature breakdown of the fluorinating compound, releasing fluorine probably as silicon fluorides at temperatures well below the melting point of the batch. The fluorine thus released escapes from the crucible. A batch was prepared by calcining gibbsite $\left(\mathrm{Al}_{2} \mathrm{O}_{3} \cdot 3 \mathrm{H}_{2} \mathrm{O}\right)$, magnesium carbonate $\left(\mathrm{MgCO}_{3}\right)$, and silicic acid $\left(\mathrm{SiO}_{2}\right)$ at a temperature of $1,000^{\circ} \mathrm{C}$ for a period of several hours, usually an overnight operation. After calcination, the fluorine compound $\left(\mathrm{K}_{2} \mathrm{SiF}_{6}\right)$ was added and the batch placed immediately in the furnace for melting and crystallization. The batch materials were of "C. P." grade.

Microcline, which is a natural-occurring feldspar, has a composition of $\mathrm{KAlSi}_{3} \mathrm{O}_{8}$ and is therefore a possible fluorophlogopite batch material. By adding 2 moles of $\mathrm{MgO}$ and 1 mole of $\mathrm{MgF}_{3}$ to 1 mole of microcline, one should have the composition of a fluorophlogopite. Unfortunately, microcline or its chemical analogue, orthoclase, is rarely found in the pure state. Sodium, which is usually present in amounts up to 3 percent in microcline, apparently prevents good crystallization of fluorophlogopite. Several attempts were made to produce a mica from a microcline feldspar with the addition of $\mathrm{MgO}$ and $\mathrm{MgF}_{2}$. These were mostly failures, as the resulting melts contained abundant amounts of glass and orthosilicates. Occasionally small mica flakes were observed under the microscope.

Efforts were made to determine the temperature of crystallization and the primary phase in melts having the composition of the normal fluorophlogopite. Both the soak-quench technique and differential thermal analysis were used. Preliminary soak-quench experiments, using $0.3-\mathrm{g}$ samples, were found to be unsatisfactory presumably because of excessive volatilization losses in such small samples. Experiments with samples of about $2.5 \mathrm{~g}$ gave much better reproducibility. Charges in sealed platinum envelopes were heated to at least $1,400^{\circ} \mathrm{C}$, well above the liquidus of this composition, cooled at rates of about $1 \mathrm{deg} / \mathrm{min}$ to the desired temperature and quenched in water. Because the centers of the melts cooled too slowly to freeze to glass, the conditions of the charges immediately adjacent to the platinum envelopes were used as the criteria. Using this method, the melting temperature was determined to be about $1,345^{\circ} \mathrm{C}$, and the primary phase was found to be fluorophlogopite. When compositions were carefully controlled, water vapor and carbon dioxide removed from the batch by precalcining, and the charge protected from excessive volatilization, the crystallization of fluorophlogopite took place on cooling without the intermediate crystallization of any other solid phase.

The procedure and apparatus used for obtaining differential heating and cooling curves are the same 


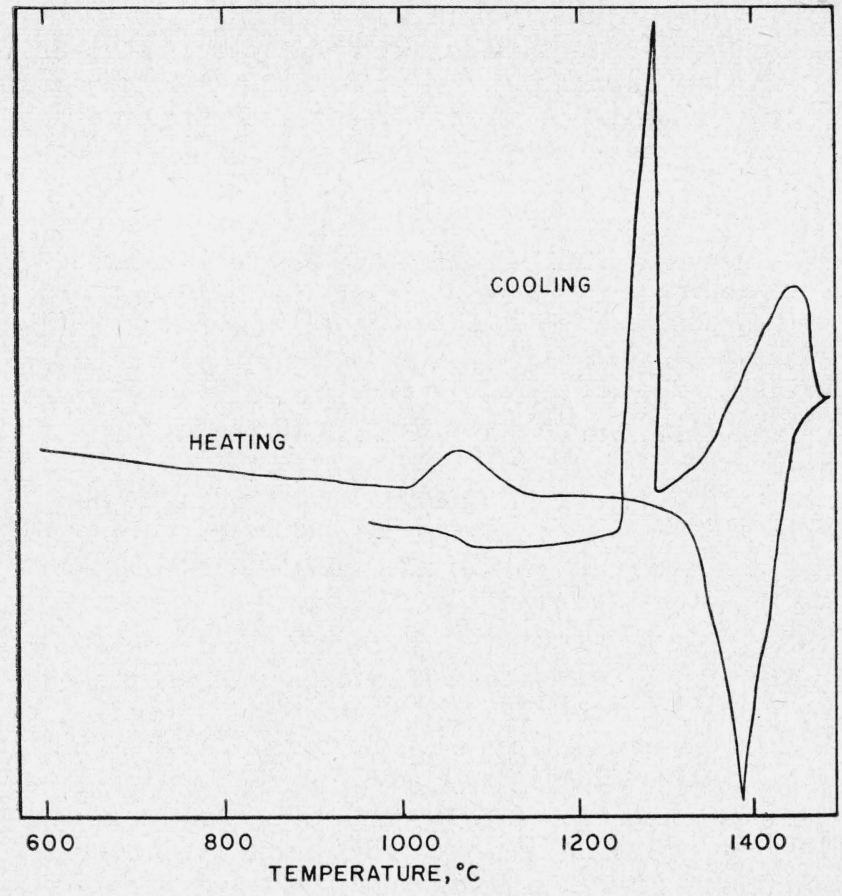

FIGURE 1.-Differential thermal curve of synthetic fluorophlogopite.

as those described by Newman and Wells [7]. Differential thermal analyses were made on a sample of clear, homogeneous, synthetic, fluorophlogopite flakes, which were carefully selected to avoid impurities. After the first run, only one thermal effect was noted on heating and one on cooling, evidently associated with melting and crystallization. As in the case of most silicates, the effects were not abrupt and the temperatures of the beginning of the endothermal effect on heating and of the exothermal effect on cooling were greatly influenced by such factors as size of charge, rate of temperature change, etc. The curve obtained from the first run of three obtained on the same sample is shown in figure 1 . The exothermic hump on heating, beginning at about $1,025^{\circ}$, is unexplained. It was absent in later runs on the same sample. The exothermic effect on cooling, beginning immediately after reversal of the furnace, is characteristic of the method and occurs before temperature change and heat flow have become uniform. The large endothermic effect on heating, starting at about $1,325^{\circ}$, is associated with melting, and the large exothermic effect on cooling, beginning at about $1,280^{\circ}$, is associated with crystallization. These heat effects may vary in temperature over a range of $30 \mathrm{deg}$, due to differences in rates of temperature change and uncontrollable experimental conditions.

\subsection{Control of Volatility}

In early crystallization experiments in which carbon or platinum crucibles were used without adequate means of controlling volatilization, such impurities as minerals of the fluorohumite group

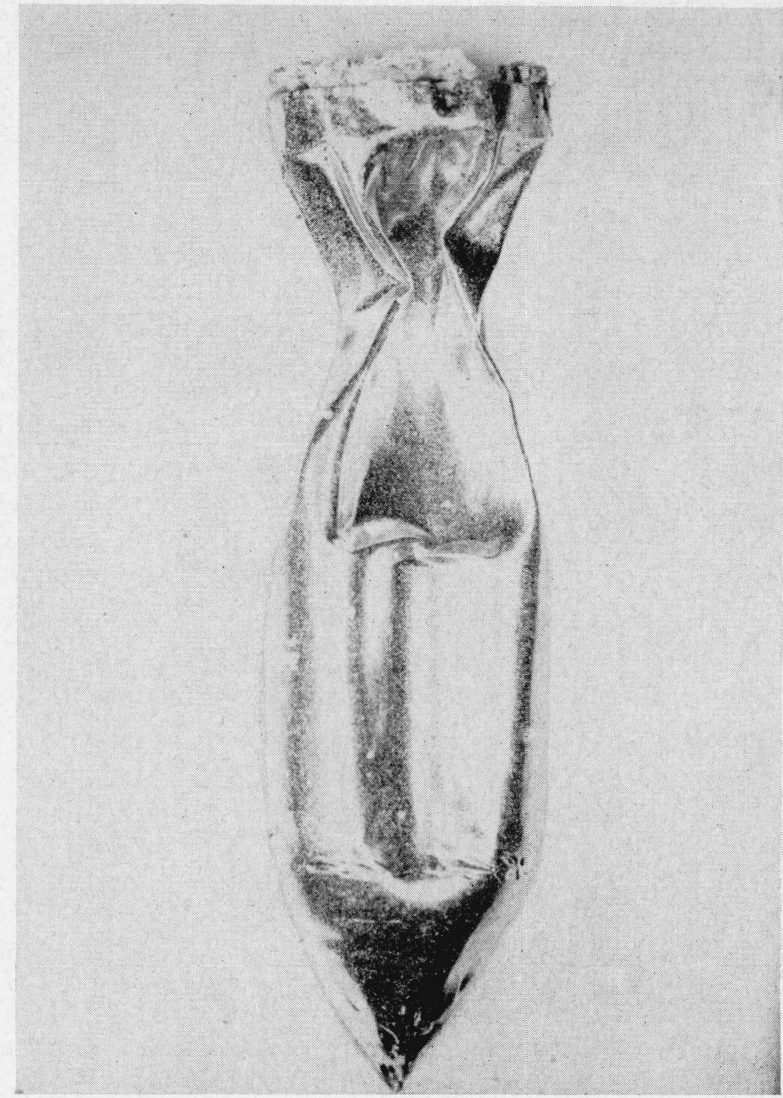

FiguRE 2. Small platinum crucible as removed from furnace, showing results of self-sealing. (Natural size.)

( $n \mathrm{Mg}_{2} \mathrm{SiO}_{4} \cdot \mathrm{MgF}_{2}$ ), forsterite $\left(\mathrm{Mg}_{2} \mathrm{SiO}_{4}\right)$, sellaite $\left(\mathrm{MgF}_{2}\right)$, spinel $\left(\mathrm{MgAl}_{2} \mathrm{O}_{4}\right)$, and glass were formed with the mica crystals. Similar impurities have been found by other investigators [8]. Several approximate weight loss determinations were made on 80 -g samples, and losses of volatiles up to 8 percent. were determined. A method was found to control volatilization by using platinum crucibles, and the losses were reduced to less than $1 / 2$ percent. The: method consisted of forming a lip on the crucible. top, projecting at right angles to the crucible walls. A platinum cover was placed over the top of the crucible so that the lip and cover were flush with. each other. When volatilization of the melt began, condensation or deposition of material high in $\mathrm{SiO}_{2}$. took place at the interface between the lip and cover, sealing the crucible. On removing the crucible at. room temperature, the upper side walls had crumpled. inward due to the formation of a partial vacuum (fig. 2). Using the sealed crucible technique, all but. glass and $\mathrm{MgF}_{2}$ impurities were eliminated from the mica crystals. These were present in amounts estimated to be less than 1 percent by volume in most. preparations.

\subsection{Composition of Crucible}

An ideal crucible might be considered as one. having the following qualifications: (a) Does not. react with the melt; (b) withstands high tempera- 
tures for long periods of time; (c) is easily molded into various forms; (d) can be reused or is inexpensive enough to be discarded.

One of the major problems in growing synthetic mica crystals is to find a crucible that is not attacked by the fluorine melt. Middle and associates [9] used crucibles composed largely of silica and alumina, but these crucibles were dissolved to such an extent by the melt that corrections in the batch composition had to be made. This method was found to be quite inadequate, for it was difficult to estimate the amount of crucible material dissolved.

In early experiments at the Bureau many ceramic bodies were tested for use as crucibles, but all were unsatisfactory as the mica melt readily attacked them. Carbon crucibles made from carbon electrodes showed promise as possible containers. The carbon did not react with the melt, and the resulting crystals could be easily removed from the crucible. The chief disadvantages of these crucibles were that finally divided carbon particles were disseminated throughout the melt, darkening the mica crystals and affecting adversely the electrical properties of the mica. To prevent the carbon crucibles from oxidizing at elevated temperatures, the crucibles had to be protected by placing them in a ceramic crucible packed with carbon or silicon carbide, which interfered with establishing proper thermal gradients within the crucible. Another undesirable feature of carbon crucibles was the relatively high porosity of the carbon bodies and the presence of bonding agents. None of the carbon crucibles tested were impervious to the volatile gases generated by the fluorine melts. With the presence of bonding agents such as clay, the crucible would be attacked by the melt, leaving voids and avenues of escape for gases.

Crucibles made of silicon carbide or lined with silicon carbide showed several undesirable features. In either case it was impossible to obtain a smooth surface, as the silicon carbide occurred as large individual crystals. These crystals acted as seeding centers for the crystallizing melt, destroying the possibility of obtaining good crystal orientation. Slight decomposition of the silicon carbide took place at the contact with the melt, releasing carbon particles, which colored the mica crystal grey.

Platinum crucibles were used in all the later crystallization experiments, as they did not appear to react with the fluorine melt. However there was a tendency for the crystals to adhere to the platinum, which not only made it necessary to peel the platinum from the crystalline cake but also oriented the mica crystals parallel to the platinum walls.

In order to economize, the inner wall only of the crucible was made of platinum. This consisted of foil 0.006 in. thick. Because platinum has little rigidity at temperatures above about $1,400^{\circ} \mathrm{C}$, the liner was supported by various means, depending on the size of the container. For small melts of about $70 \mathrm{~g}$, the foil container was supported in a bed of granular refractory material contained in an outer, cylindrical ceramic crucible. For larger melts, the

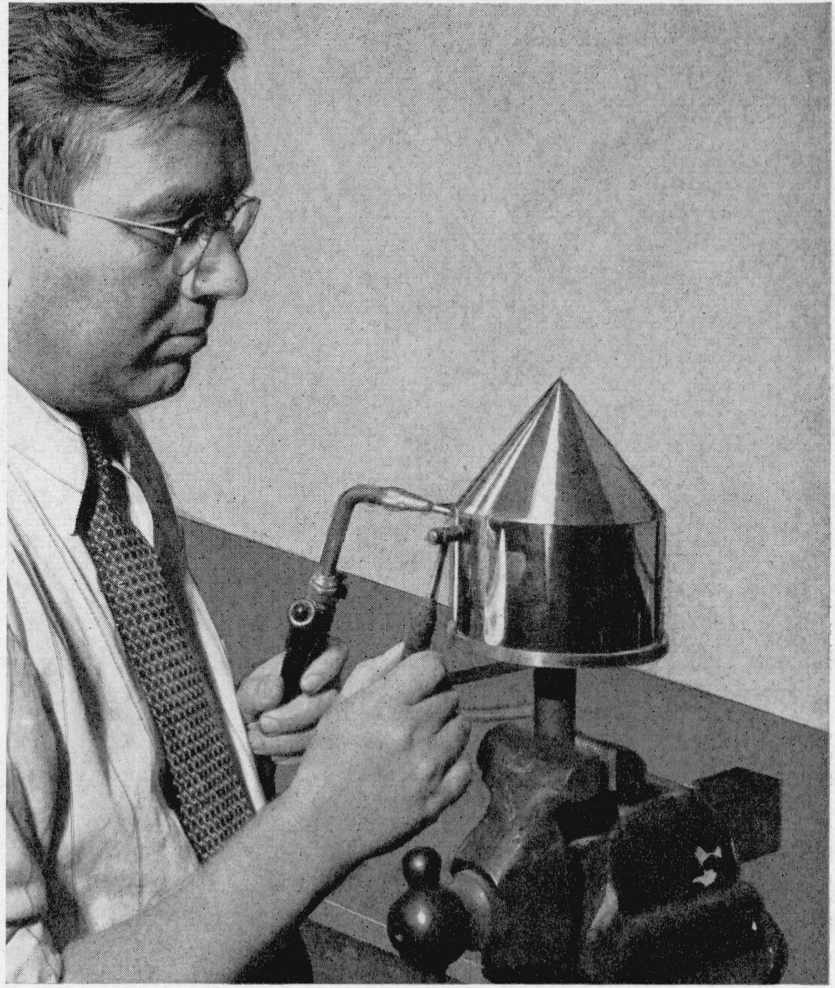

Figure 3. Cylindrical crucible with conical base. Platinum walls being welded together on a steel mandrel.

platinum liner was fitted snugly into a ceramic crucible of the correct shape. Joints in the foil were welded with a blow torch on a steel mandrel (fig. 3), and care was taken to make the completed crucible leak-proof.

\subsection{Thermal Gradients}

The disposition and steepness of temperature gradients in the crystallizing melt are of critical importance in the control of size and orientation of the mica sheets. Obviously, these are affected by the characteristics of the furnace and the shape and size of the crystallizing crucible.

As preliminary experiments indicated a melting temperature of fluorophlogopite near $1,350^{\circ} \mathrm{C}$, furnaces were necessary that could produce a temperature within the crucible well above the melting temperature, say $1,500^{\circ} \mathrm{C}$, in order to assure complete removal of possible nucleation centers of unmelted material. To meet this requirement, two furnaces were designed and built: (1) a platinum-wire resistance furnace for crucibles with a capacity of about $70 \mathrm{~g}$ (fig. 4), and (2) a Globar resistance furnace for crucibles with a capacity of about $8 \mathrm{~kg}$ (fig. 5).

The smaller furnace contained a cylindrical refractory core with an inside diameter of $2 \frac{1}{2}$ in., on which was wound the main heating element consisting of 20-gage 80-percent platinum-20-percent rhodium wire. The winding covered $9^{1 / 4}$ in. of the core with 55 turns of the wire. A booster element made of the 


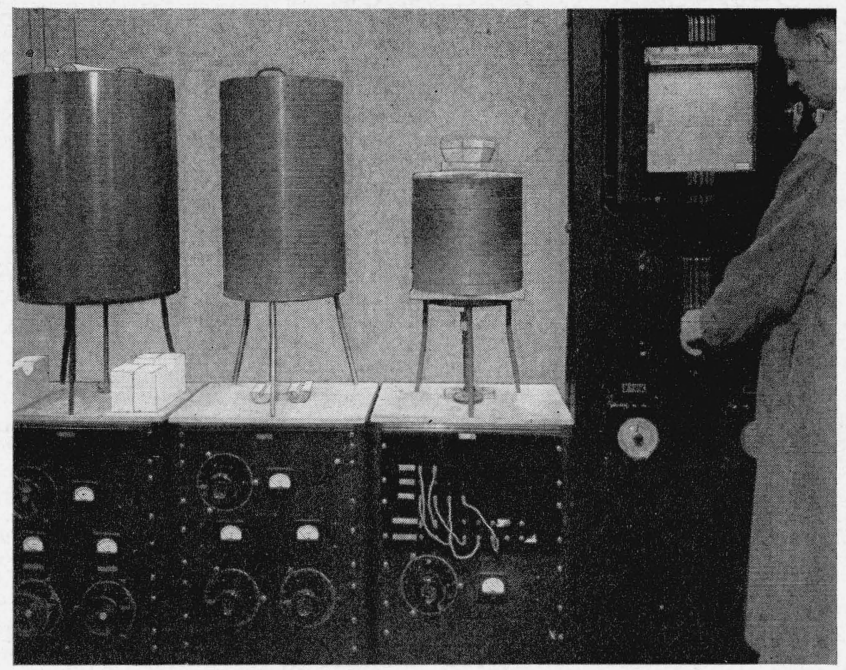

Figure 4. Platinum resistance furnaces for crystallization and phase determination work.

same gage and composition wire was wound on a cylindrical core of 3 -in. diameter. This element was 3 -in. long, arranged coaxially with the inner core and covered the upper portion of the main element. Each winding was connected to a separate auto-transformer. The primaries of both transformers were connected to an on-off proportional program controller. Thus, the desired temperature gradient in the furnace could be maintained while the temperature in the furnace could be lowered at a predetermined rate. Experience showed that cooling rates of as low as $0.2 \mathrm{deg} / \mathrm{hr}$ could be obtained from $1,450^{\circ}$ to $1,200^{\circ} \mathrm{C}$.

The larger furnace was heated by means of Globar elements. For use with a crucible with circular section, the muffle was cylindrical with a 7 -in. bore and a height of $20 \mathrm{in}$. The Globar elements were arranged in a horizontal square grid, four elements to a set, with three sets arranged vertically. The upper two sets were separated from the lower set by a horizontal baffle made of insulating refractory. In most runs, only the upper two sets were in use. These were controlled by an automatic potentiometer on an on-off control of about 15 percent of the total power, and through a platinum, platinum-rhodium thermocouple placed in the heating chamber. Temperatures could be controlled to within $\pm 10 \mathrm{deg} C$ at $1,400^{\circ} \mathrm{C}$. With the slowest cooling rates used, $0.2 \mathrm{deg} / \mathrm{hr}$ the furnace control was not sufficiently sensitive, therefore, fluctuations far exceeded the cooling rate required.

In using crucibles with elongated horizontal cross section placed in a rectangular muffle, the Globar elements were disposed parallel and close to the broad sides of the crucible and were removed from the narrow sides.

Two types of platinum-foil crucibles were used in the smaller furnace: (1) a form with cylindrical walls and a conical bottom, and (2) a form with an elongated horizontal cross section and wedge-shape bottom, similar to but smaller than that shown in

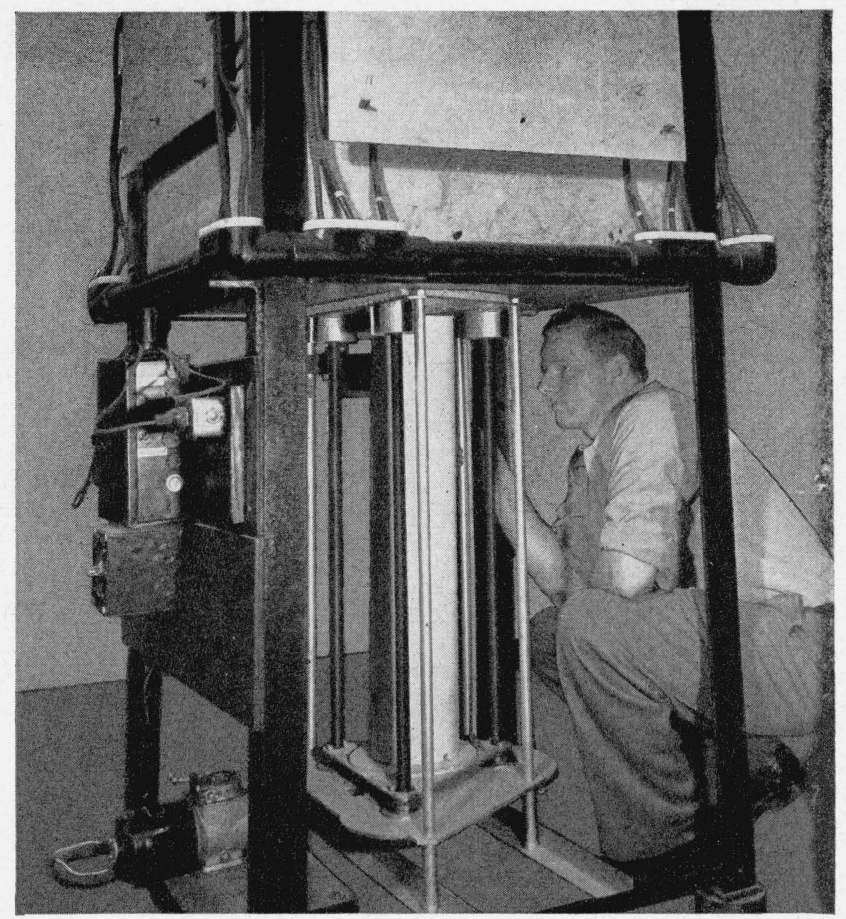

Figure 5. Large Globar Crystallizing furnace with elevator lifting apparatus underneath.

Variable speed motor at lower left lowers and raises elevator.

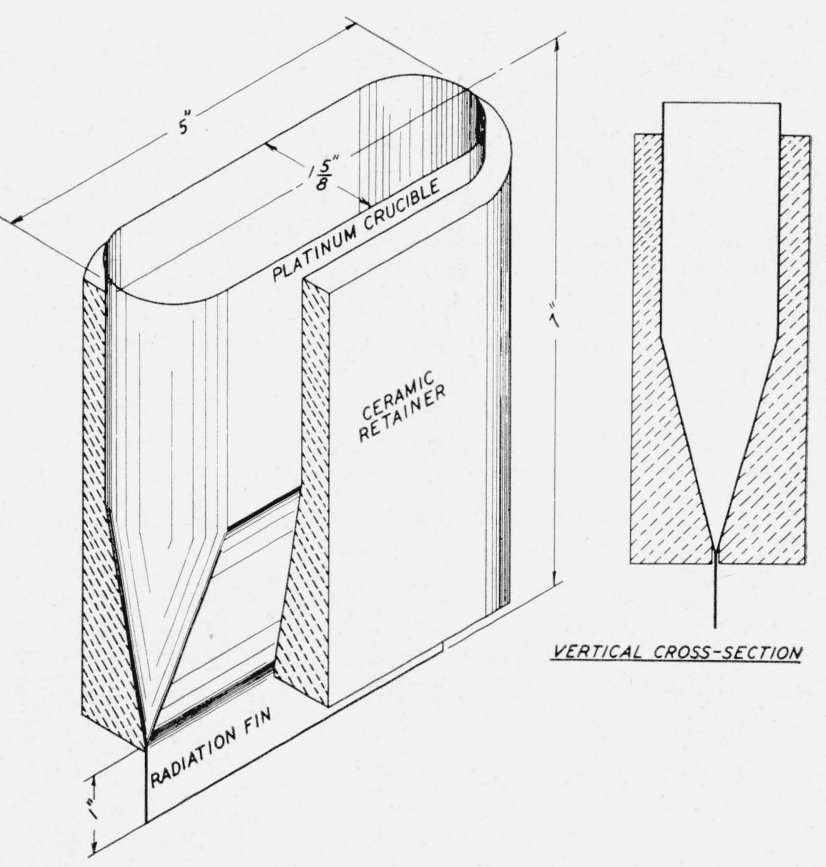

FiguRE 6. Drawing of large elliptical crucible showing supporting ceramic container and radiation fin at base.

figure 6 . The 110 melts made in the smaller furnace provided useful information on volatilization losses, orientation control, etc., for the design of experiments in the larger furnaces. Various arrangements of cooling fins attached to the bases of both shapes 
of crucible were tried in order to vary the thermal gradients (figs. 6 and 7 ).

The rate of cooling and the steepness of the vertical temperature gradient were varied in order to determine the effect on size of crystals and vertical orientation. The rate of cooling was varied from 15 to 0.2 $\operatorname{deg} \mathrm{C} / \mathrm{hr}$, and the gradient from top to bottom of the crucible was varied between $15^{\circ}$ and $90^{\circ} \mathrm{C}$. In general, it was found that the slower the rate of cooling and the steeper the temperature gradient, the larger the crystals and the better the vertical orientation. Cooling rates faster than $1 \mathrm{deg} \mathrm{C} / \mathrm{hr}$ and gradients less and $50^{\circ} \mathrm{C}$ provided small, randomly oriented crystals with inclusions of gas cavities (fig. 8) and with associated impurities of glass and $\mathrm{MgF}_{2}$.

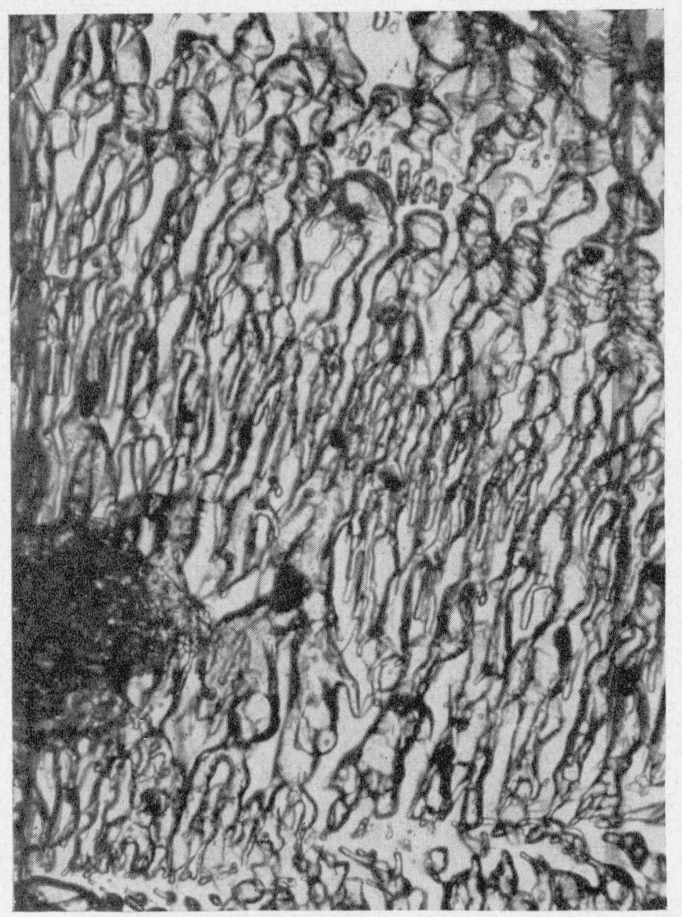

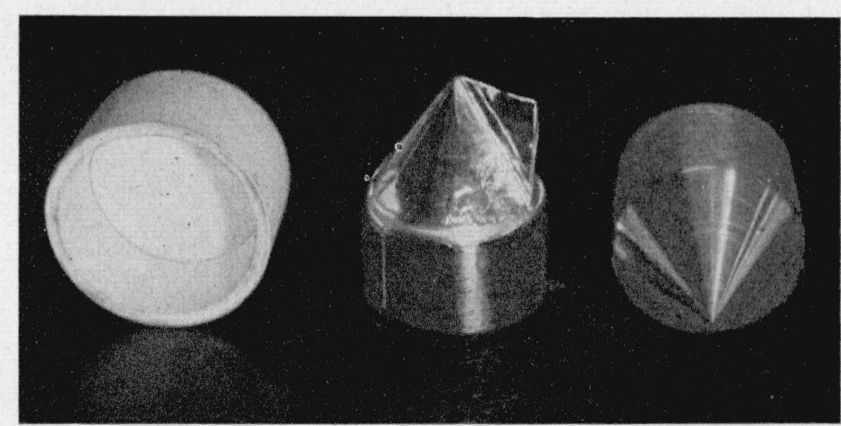

FIgURE 7. Platinum crucible (center) showing radiation fin welded to cone portion of crucible.

(Left) Ceramic retaining crucible; (right) steel mandrel used to shape platinum erucible.

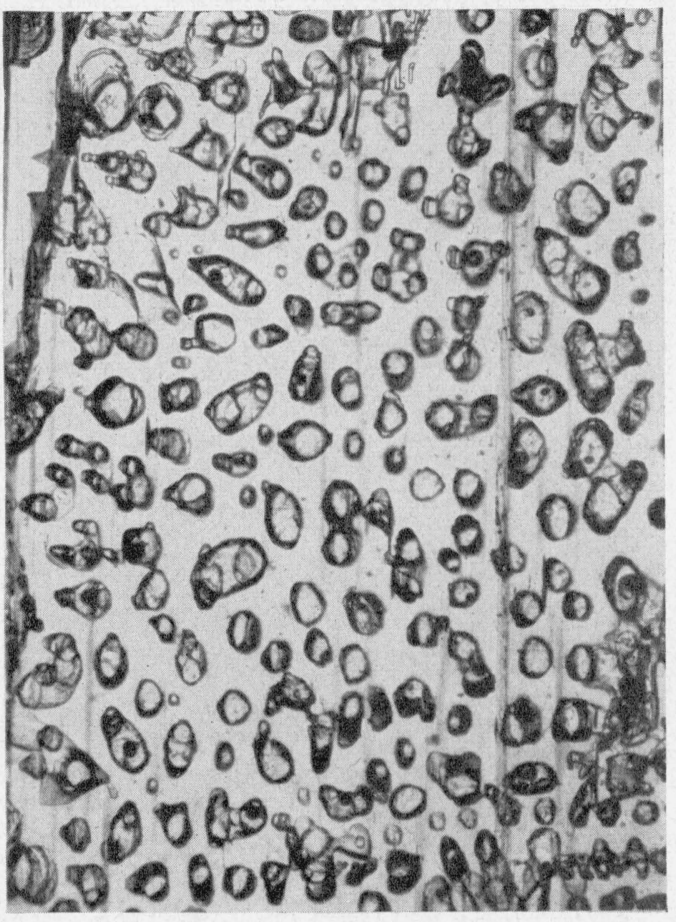

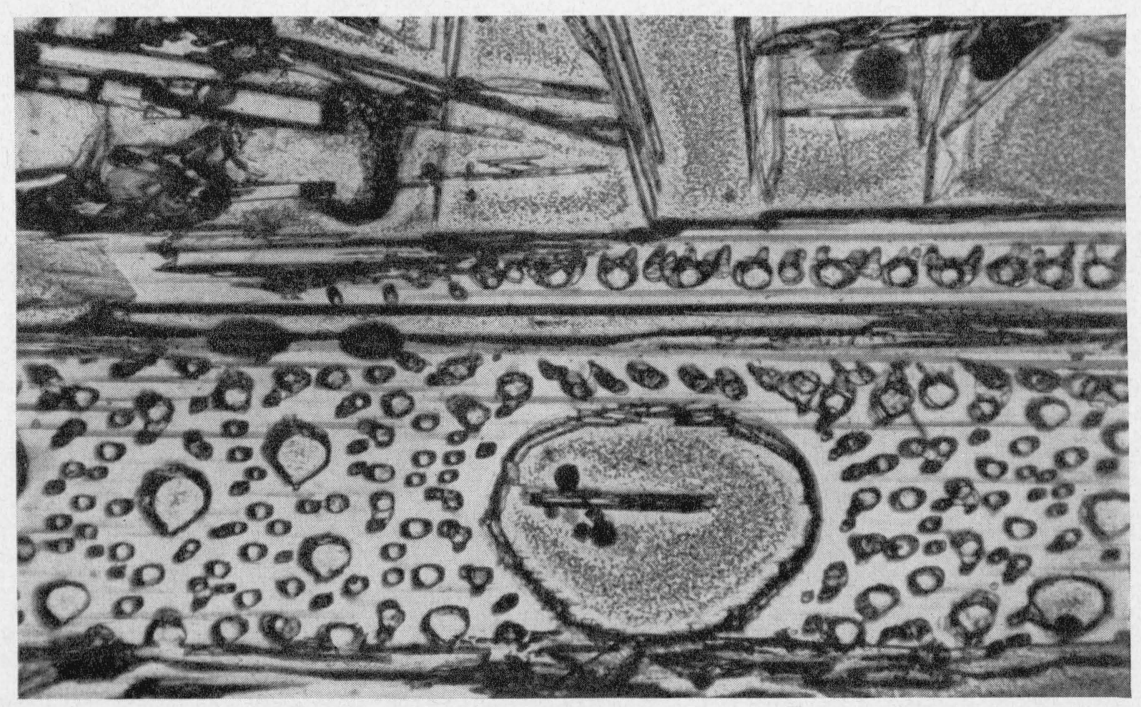

FIGURE 8.-Thin sections of synthetic phlogopite taken at right angles to the cleavage, showing cavities in various attitudes ( $X 40$ ). 


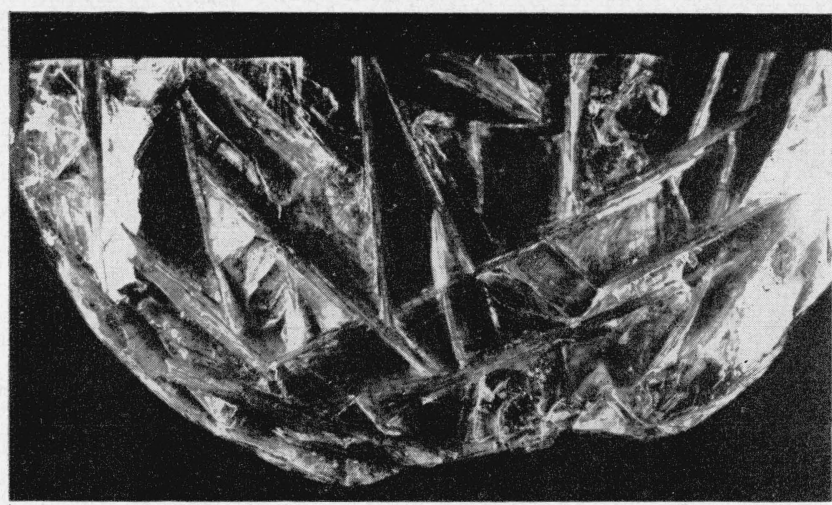

Figure 9. A view of the horizontal surface (one-half cake) of a large mica melt, showing good vertical orientation but lack of parallel orientation.
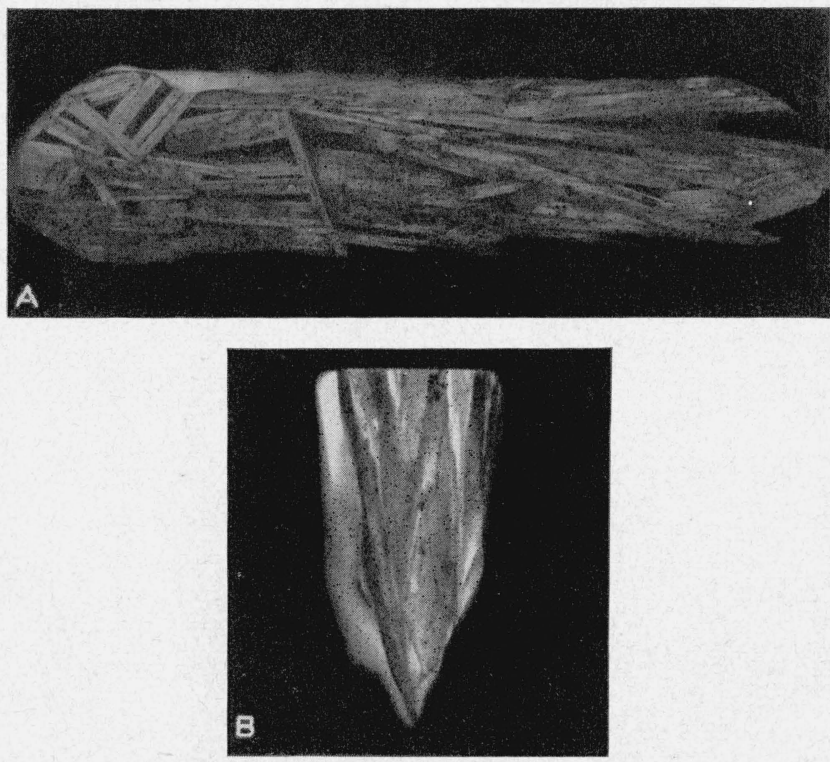

Figure 10. Mica crystals showing a preferred parallel orientation parallel to broad sides of small crucible.

(A) Plan section; (B) cross section. Natural size.

In order to assure the grow th of large crystals, it is necessary to reduce the number of nuclei available for new crystal formation. For this purpose, the bottoms of the crucibles were either reduced to the apex of a cone or to the trough at the base of a wedge. In the large crucible of the shape shown in figure 7 , good development of vertical orientation was obtained, but the lack of horizontal orientation produced nonparallel crystals that were limited in breadth because of intersections with other growing crystals (fig. 9 ).

To obtain parallel lateral orientation and to prevent the intersecting growth of crystals, crucibles having the shape shown in figure 6 were used. As indicated from the small melt shown in figure 10 and the large melt shown in figure 11, a fair degree of lateral orientation was thus achieved. All of the crystallization experiments made in platinum, however, showed that both the surface of the melt and

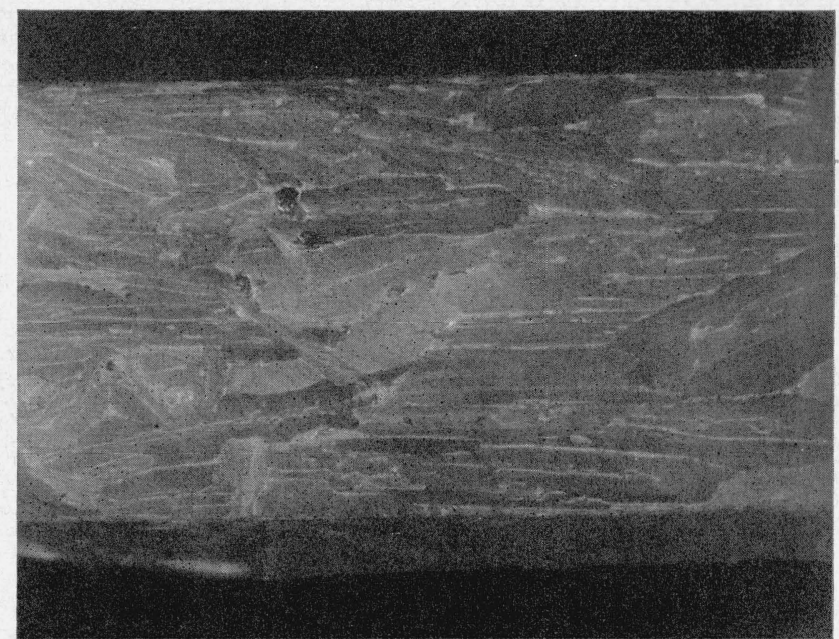

FiguRE 11. Mica crystals showing a preferred parallel orientation to broad sides of crucible.

One-half surface of large melt $(\times 1.3)$

the surface against the platinum container exerted a marked effect on the orientation of the mica crystals. In one experiment made in the small furnace in platinum, the temperature gradient was deliberately reversed, and cooling took place from the top down. With the very slow rate of cooling used, $0.2 \mathrm{deg} \mathrm{C} / \mathrm{hr}$, a single horizontal crystal of mica formed over the entire surface of the melt, and crystallization continued until it reached a thickness of about $3 \mathrm{~mm}$. Beyond this thickness, new crystals were formed predominantly parallel to the temperature gradient. In most well-crystallized melts, the crystals next to the platinum walls show a marked tendency to be parallel to the contact.

Attempts were made to obtain large crystals of mica by seeding the melt with a single mica flake at various temperatures before freezing took place. In all cases, the flakes either melted or had no effect on orientation. Pieces of corundum with known crystal orientation were introduced into melts to act as seeding centers to give a preferred orientation to the mica nuclei. There was no indication that corundum acted in orienting the mica crystals. A. Dietzel [10] claimed that a magnetic field imposed upon a crystallizing melt did have a crystal orientation effect. According to his data, the synthetic mica is slightly paramagnetic, and weak fields of about 50 to 100 gauss are sufficient to produce an orientation effect. In two experiments using a series-wound horseshoe magnet that produced about 70 gauss, no magnetic effect could be observed on a synthetic mica flake. The technique of orienting mica crystals by means of a magnetic field was thought to be impracticable, and further experiments were abandoned.

The Kyropoulos [11] technique of growing crystals was attempted with a mica melt. The essential feature of this technique is to form a single crystal by slowly withdrawing a seed from a melt. The surface of the melt is kept near but slightly above the freezing point, and crystallization takes place at the interface of the melt and the crystal. A platinum 
plate 0.002 in. thick was dipped into the melt and then slowly withdrawn. Platinum has good thermal conductivity, and it was expected that a seed crystal would form at the tip of the plate, which would be below the freezing point of the melt. Trouble was experienced in keeping the melt just above freezing temperature. When the plate was dipped, either the surface of the melt would freeze completely or no crystals would form at all. This technique did not appear to offer good results unless better control of the thermal relation between the surface of the melt and the plate could be obtained.

\section{Properties of Synthetic Mica}

The properties of synthetic fluorophlogopite are essentially the same as its natural analogue. In thin flakes, the mica is clear and transparent. As in the natural micas, the cleavage is the most characteristic property of the synthetic mica. The cleavage occurs parallel to the (001) crystallographic plane, and in thin laminas, the flakes are elastic but less so than natural phlogopite. The mica appears to have a hardness equal to that of natural phlogopite. Its specific gravity is about 3.00 , as measured on a Berman Torsion Balance. The specific gravity is troublesome to obtain, as the edges of the mica flakes are often fraved and will give erroneous results.

The optical constants of the synthetic mica were measured, using petrographic microscope techniques. The mica is negative in character, with the optical plane being parallel or nearly parallel to $b(010)$. The optic angle $2 \mathrm{~V}$ is about $9^{\circ}$, with measured indices of refraction of $\beta=1.545, \gamma=1.547$, and $\alpha$ calculated to be 1.519 .

The dielectric constant and dissipation factor of six specimens were measured at the Bureau's Inductance and Capacitance Section. The measurements were made at $25^{\circ} \mathrm{C}$ and at three frequencies: 100 , 1,000 , and $100,000 \mathrm{cps}$. The values of dielectric constant at $1,000 \mathrm{cps}$ vary from 5.0 to 7.0 , with an average value of 6.3. As the specimens were small, $1 / 2$ to $3 / 4$ in. in their longest direction, errors in measurement of dielectric constant of as much as 10 percent were to be expected. The spread in values of some 40 percent indicates a certain amount of variability in the dielectric constant of the material. The dielectric constant decreased slightly (about 2 or $3 \%$ ) as the frequency was changed from 100 to $100,000 \mathrm{cps}$. Values of the dissipation factor varied from 9 to $300 \times 10^{-4}$ when measured on different days. The cause for these changes with time is not known, but all of the changes were in the direction of smaller values. The average value at 1,000 $\mathrm{cps}$ was about $60 \times 10^{-4}$. The value of the dissipation factor seemed to decrease slightly with frequency between 100 and 100,000 cps.

The hygroscopic character of the mica or the ability of mica to absorb and retain water was determined by Donald Hubbard of the Bureau's Glass Section. In general, the method consisted of weighing the water sorbed upon exposing approximately $1.5 \mathrm{~g}$ of powdered mica that passed a 150 mesh standard sieve to the high (approximately 98\%) humidity maintained by a saturated solution of $\mathrm{CaSO}_{4} \cdot 2 \mathrm{H}_{2} \mathrm{O}$. The results are expressed in water sorbed in milligrams per cubic centimeter at the end of 1 and 2 hrs. For comparison, a natural phlogopite from Argentina and three glasses have been included.

\begin{tabular}{|c|c|c|}
\hline & \multicolumn{2}{|c|}{ Water sorbed in- } \\
\hline & 1 hour & 2 hours \\
\hline $\begin{array}{l}\text { Synthetic phlogopite } \\
\text { Argentina phlogopite } \\
\text { Pyrex glass } \\
\text { Vycor glass } \\
\text { No. } 015 \text { glass }\end{array}$ & $\begin{array}{l}\mathrm{mg} / \mathrm{cm}^{3} \\
46 \\
56 \\
16 \\
11 \\
88\end{array}$ & $\begin{array}{c}m g / \mathrm{cm}^{3} \\
57 \\
74 \\
20 \\
13 \\
191\end{array}$ \\
\hline
\end{tabular}

Thermally, the phlogopite micas have a higher breakdown temperature than do the other micas, and this holds true for the sythetic fluorophlogopite. Several clear mica flakes were subjected to a temperature of $1,000^{\circ} \mathrm{C}$ for a period of 3 days. The surface of the mica had a cloudy appearance, and it was noticed that mosaic structures had formed (fig. 12). Microscopically, the thermally treated material had approximately the same optical constants as did the untreated mica, and an X-ray diffraction pattern gave essentially the same pattern as for the untreated materials.

Under the direction of B. L. Bean of this Bureau, a chemical analysis was made on selected clear flakes of synthetic mica, containing no visible impurities.

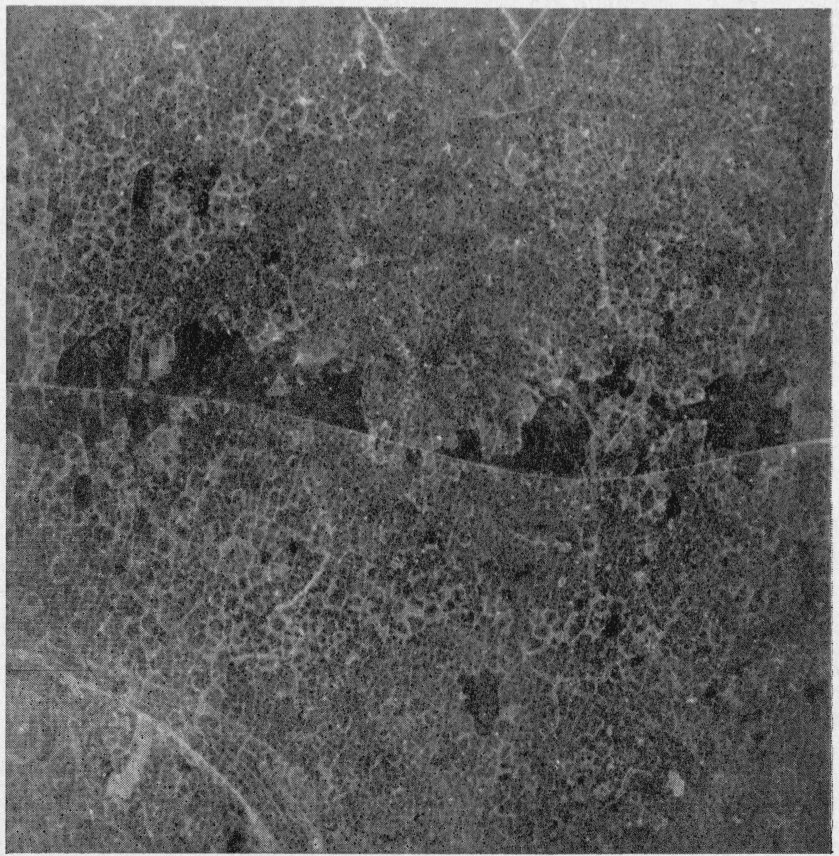

Figure 12. Mosaic structure formed on surface of mica crystals after heat treatment.

A scratch line from right to left has broken off many segments, leaving a clear area underneath $(\times 20)$. 
The results in weight percent are:

\begin{tabular}{|r|r|}
\hline & \\
$\mathrm{SiO}_{2}$ & 41.87 \\
$\mathrm{Al}_{2} \mathrm{O}_{3}$ & 12.97 \\
$\mathrm{MgO}_{2}$ & 28.27 \\
$\mathrm{~F}$ & 8.52 \\
$\mathrm{~K}_{2} \mathrm{O}_{2} \mathrm{O}_{2}$ & 0.12 \\
$\mathrm{Na}_{2} \mathrm{O}_{-}$ & 102.69 \\
Equivalent, $\mathrm{O}=\mathrm{F}$ & 3.51 \\
\hline Total & 99.18 \\
\hline
\end{tabular}

X-ray diffraction patterns were made of selected mica flakes, and these were compared with a natural phlogopite from Canada obtained from the U. S. National Museum. The patterns were made on a X-ray Geiger counter, using copper radiation. The synthetic and the natural patterns are essentially the same with minor differences in intensities and a small difference in $d$-spacing, as can be observed at the higher angles of $2 \theta$ (fig. 13). As mica has a highly developed cleavage, the problem of getting a random orientation of the powder grains is almost impossible, hence the intensities are not truly representative of the mica. The small difference in $d$ spacing may be due to the presence of iron in the natural sample and to the fact that the synthetic mica does not contain any $(\mathrm{OH})$ ions.

Impurities were observed in all the crystallization experiments, and their presence apparently depended in part upon the loss of volatile constituents. In early crystallization experiments, using carbon and uncovered crucibles, where volatilization losses were high (about 8 to $10 \%$ by weight) impurities of forsterite, norbergite, chondrodite, and glass were present in appreciable quantities. They occurred as milky, or cloudy, patches in the plane of the mica cleavage. The orthosilicates were often inclosed in glass, or they occurred in branching structures (fig. 14). In later experiments, when volatilization was controlled by sealing the crucible, the orthosilicates were eliminated, but $\mathrm{MgF}_{2}$ and glass remained as impurities. The glass had a mean index of about 1.51. The impurities occurred in small amounts estimated to be less than 1 percent by volume, and these were randomly scattered throughout the crystals. Mica crystals as large as 4 in $^{2}$ in area and free from impurities were obtained from melts in the large globar furnace. Structural defects in the form of gas bubbles were observed in those melts that were cooled quickly (greater than $1 \mathrm{deg} \mathrm{C} / \mathrm{hr}$ ).

These bubbles, or cavities, appeared to occur in planes paralleling the mica cleavage planes. It was observed that melts cooled at slower speeds contained less structural defects and fewer impurities.

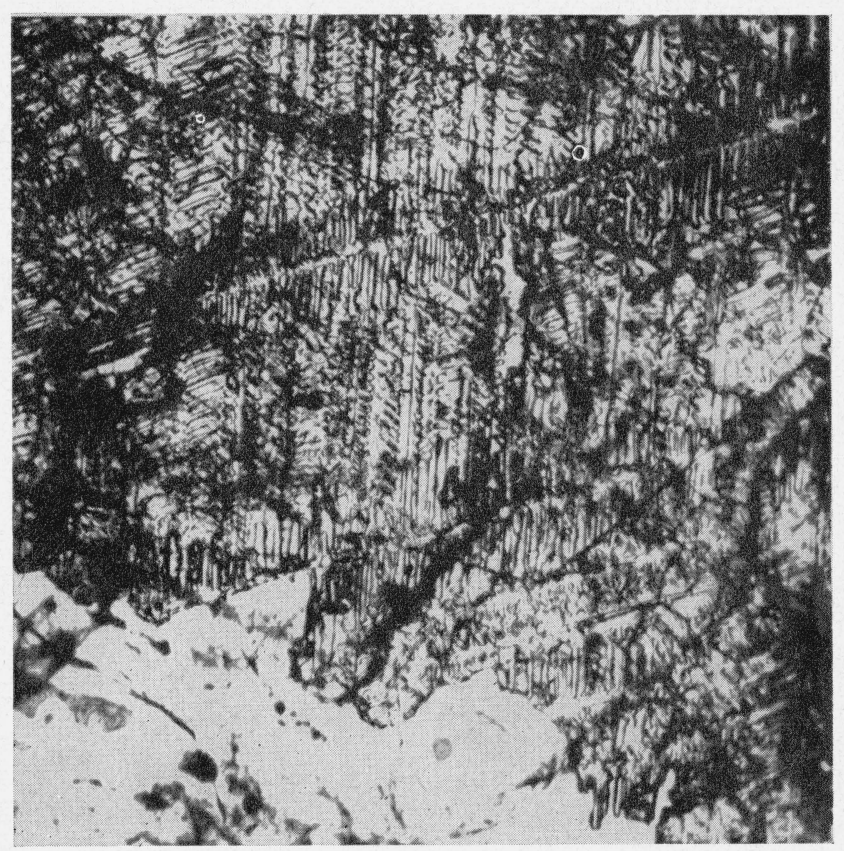

FiguRE 14. Mica flake parallel to cleavage.

Clear mica in lower portion of photograph. Remaining area shows dendritic structures $(\times 30)$.

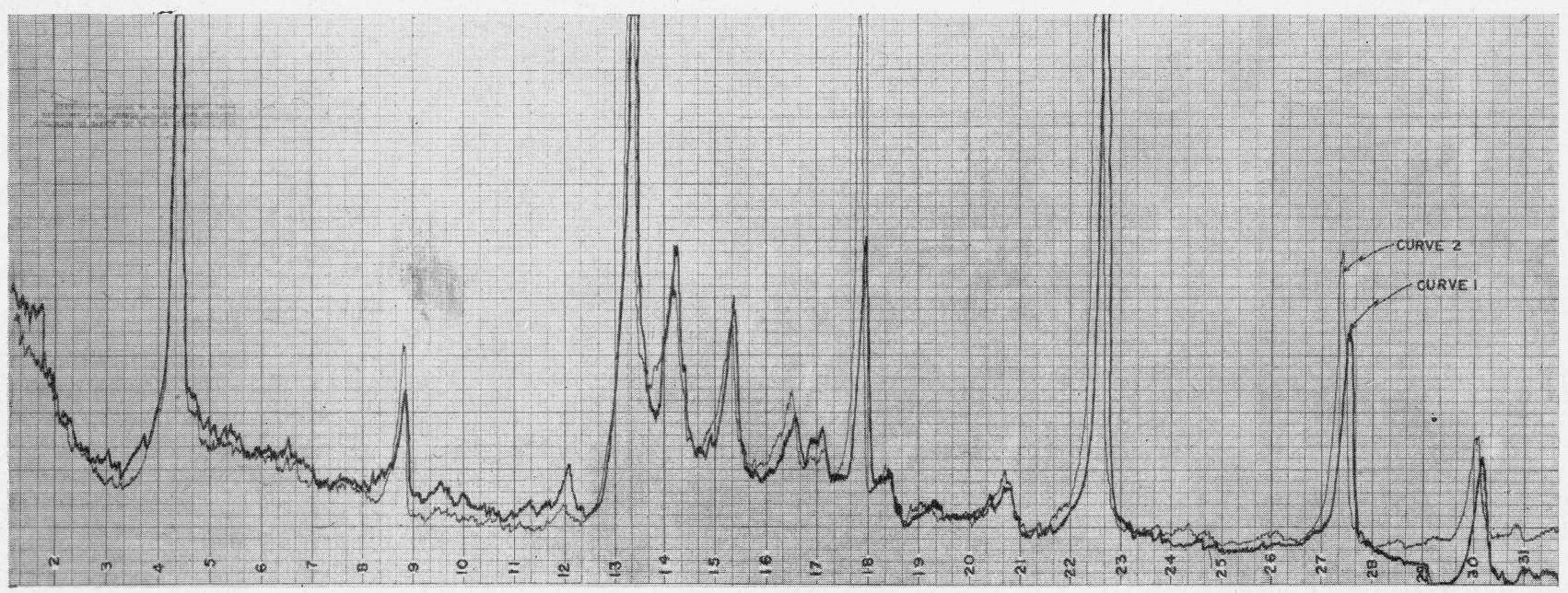

FiguRE 13. X-ray powder diffraction patterns of natural phlogopite (1) and synthetic phlogopite (2). 


\section{Summary}

A synthetic fluorophlogopite mica having the approximate formula of $\mathrm{K}_{4} \mathrm{Mg}_{12} \mathrm{Al}_{4} \mathrm{Si}_{12} \mathrm{O}_{40} \mathrm{~F}_{8}$ can be crystallized from a melt at atmospheric pressures. The ingredients that produced the best crystals consisted of:

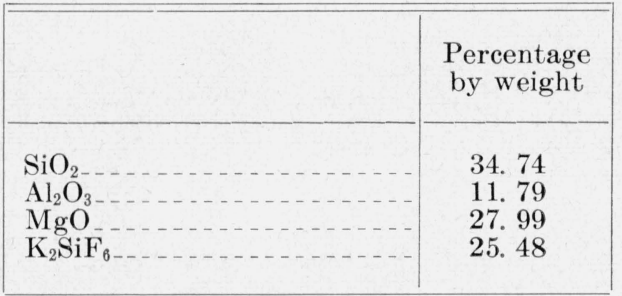

This composition melts at about $1,345^{\circ} \mathrm{C}$, and when it is cooled slowly in the order of magnitude of $0.3 \mathrm{deg} \mathrm{C} / \mathrm{hr}$, good mica crystals can be obtained. To grow large crystals it is necessary to obtain a preferred orientation of the individual crystals, otherwise growth is interrupted by intersection of one crystal with another. The disposition of the thermal gradient in a mica melt is the most important factor governing the orientation of a growing crystal, and it was found that mica crystals grow with their cleavage planes parallel to the direction of the gradient. The majority of the mica experiments were performed in closed platinum crucibles, using electric resistance furnaces.

In general, the physical, chemical, and electric properties of the synthetic fluorophlogopite, are essentially the same as those of a natural phlogopite, with the exceptions that the synthetic mica tends to be a little more brittle and does not contain $(\mathrm{OH})$ ions. Thermally, it has a higher breakdown temperature, and for short periods of time can withstand temperatures of $1,200^{\circ} \mathrm{C}$ without noticeable changes.

\section{References}

[1] J. H. L. Vogt, Berg- u. hüttenmänn. Zeitung 4\%, 197 (1888)

[2] F. A. Fouqué and A. M. Lévey, Compt. rend. 113, 283 (1891).

[3] C. Doelter, Compt. rend. 2, 178 (1888) ; 1, 1 (1897).

[4] P. Hautefeville, Compt. rend. 104, 508 '(1887).

[5] L. P. de Saint-Gilles and K. Chrustschoft, Mineralog. petrog. u Mitt. 9, 55 (1887).

[6] D. P. Grigor'ev, the preparation of artificial magnesium mica, Zentr. Mineral. Geol., p. 219 to 223 (1934A); the crystallization of amphibole and mica from artificial silicate melts, Zentr. Mineral. Geol., p. 117 to $123(\mathbf{1 9 3 5 A})$; the role of fluorine, chlorine, and tungsten oxide compounds in the artificial formation of magnesium micas, Mém. soc. russe. minéral. 66, 118 to 123 (1937); Synthesis and study of phlogopite, Compt. rend. Sci. URSS 43, 63 to 65 (1944).

[7] E. Newman and L. W. Wells, Effect of some added material to dicalcium silicate, J. Research NBS 36, 137 (1946) RP1696.
[8] W. Eitel, The synthesis of fluorine mica of the phlogopite group, Fiat Final Report No. 747 (1946).

[9] Bennett'S. Ellefson, Crucibles for synthetic mica development, Fiat Final Report No. 1050 (1947).

[10] Paul M. Tyler, Synthetic mica research, Fiat Final Report No. 746 (1946).

[11] S. Kyropoulos, Z. anorg. chem. 154, 308 (1926); Z. Physik 63, 849 (1930).

\section{Additional References on Mica Synthesis}

Paul M. Tyler, Synthetic mica research, Fiat Final Report No. 746 (1946).

W. Eitel, The synthesis of fluorine mica of the phlogopite group, Fiat Final Report No. 747 (1946).

W. Eitel, Crystallochemical and microscopic investigation of synthetic phlogopites, Fiat Final Report No. 748 (1946).

W. Eitel, Regular intergrowth of synthetic phlogopite with hydrous mica, Fiat Final Report No. 749 (1946).

Rustum, Roy, Decomposition and resynthesis of the micas, J. Am. Ceram. Soc. 32, No. 6 (1949).

Tokiti Noda, Translation of seven Japanese papers on the synthesis of fluorine micas, Tachino, translator. Section TIS Geological Survey Branch, Intelligence Division, Office of the Engineer General Headquarters, Far East Command (1945).

Chemical composition and optical properties of synthetic mica, and microscopic studies, J. Soc. Chem. Ind. (Japan) 46, No. 8, 760 to 762 (1943).

-, Composition of fused substances from fluosilicates and mica crystallization temperature (Report No. 2); J. Soc. Chem. (Ind. (Japan) 46, No. 10, 1082 to 1085 (1943).

- Composition of fused substances from fluosilicates and mica crystallization temperature (Report No. 1); J. Soc. Chem. Ind. (Japan) 46, No. 9, 921 to 923 (1943).

- Composition of fused substances from fluosilicates and mica crystallization temperature (Report No. 3) J. Soc. Chem. Ind. (Japan) 4\%, No. 4, 320 to 322 (1944).

-, Synthesis of boronic phlogopite, J. Soc. Chem. Ind. (Japan) 47, No. 6, 499 to 502 (1944).

-, Composition of fused substances from fluosilicates and mica crystallization temperature (Reports No. 4 and 15 ) J. Soc. Chem. Ind. (Japan) 47, No. 7, 623 to 627 (1944). - Composition of fused substances from fluosilicates and mica crystallization temperature (Reports 6 and 7) J. Soc. Chem. Ind. (Japan) 48, No. 1, 14 to 15 (1945).

D. P. Grigor'ev, The preparation of artificial magnesium mica, Zentr. Mineral. Geol., p. 219 to 223 (1934A).

D. P. Grigor'ev, The role of fluorine, chlorine, and tungsten oxide compounds in the artificial formation of magnesium micas, Mém. soc. russe. minéral. 64, 347 to 354 (1935).

D. P. Grigor'ev, the crystallization of amphibole and mica from artificial' silicate melts, Zentr. Mineral. Geol., p. 117 to $123(\mathbf{1 9 3 5 \mathbf { A }})$.

D. P. Grigor'ev, Synthesis and study of phlogopite, Compt. rend. Acad. Sci. URSS 43, 63 to 65 (1944).

J. W. Gruner, Ammonium mica synthesized from vermiculite, Am. Mineral. 24, 428 to 433 (1939).

J. W. Gruner, Formation and stability of muscovite in acid solutions at elevated temperatures, Am. Mineral. 24, 624 to 628 (1939).

R. Reichmann and V. Middle, Production of synthetic mica, A Report on the synthetic mica at Siemens-Schuckert, issued in 1942.

V. Middel, Experiments on the production of synthetic mica in large experimental apparatus, Office of the Publication Board, Department of Commerce, PB32546 (1947).

Washington, December 6, 1951. 